\title{
Intraventricular meningiomas: a consecutive series of 22 patients and literature review
}

${ }^{1}$ Kristina M. Ødegaard stud. med., ${ }^{1,2}$ Eirik Helseth MD, PhD, ${ }^{3}$ Torstein R. Meling MD, Dr. phil.

${ }^{1}$ Faculty of Medicine, University of Oslo

${ }^{2}$ Department of Neurosurgery, Oslo University Hospital, Ullevål

${ }^{3}$ Department of Neurosurgery, Oslo University Hospital, Rikshospitalet

\section{Corresponding author:}

Torstein R. Meling, MD, Dr. phil.

Senior Consultant

Department of Neurosurgery, Rikshospitalet

Oslo University Hospital

N-0027 Oslo, Norway

Phone: +4723074843

Fax: +4723074310

E-mail: torstein.meling@rikshospitalet.no 


\section{ABSTRACT \\ Objective:}

Intraventricular meningiomas (IVMs) are rare tumors of which the majority is located in the lateral ventricles. Most published series on the subject include only a few patients. We analyzed our series of IVMs with a special interest in clinical features, outcome and complications related to surgery.

\section{Material \& Methods:}

22 patients underwent resection of IVMs from 1990 to 2010 at Oslo University Hospital. Surgical and medical records were retrospectively analyzed.

\section{Results:}

The IVMs were located in the trigonum of the lateral ventricles $(20 / 22)$, in the third ventricle (1/22) and in the fourth ventricle (1/22). The most common symptoms and signs were headache, vertigo, nausea/vomiting, mental disturbances, balance impairment and corticospinal tract signs. Visual field deficit was present preoperatively in two patients. Tumors of the lateral ventricles were resected via a transcortical parieto-occipital approach; the tumors in the third and fourth ventricle via a frontal transcortical and suboccipital route, respectively. Complete tumor resection was achieved in all but one case. Histology was WHO grade I in 20/22 and grade II in $2 / 22$. Surgical mortality was $0 \%$. Most symptoms and signs resolved after surgery. The most common complication was visual field defect: four patients developed new-onset contralateral homonymous quadrant anopia and one patient developed hemianopia.

\section{Conclusions:}

Symptomatic IVMs should be resected, and most symptoms and signs resolve after surgery. The main challenge is to avoid damaging the geniculucalcarine tract when resecting IVMs in the trigonum. Preoperative diffusion tensor imaging-based tractography to map the geniculocalcarine tract should therefore be mandatory before selecting the surgical approach. 


\section{KEY WORDS:}

Complications - Craniotomy - Intracranial tumor - Intraventricular meningioma Surgical mortality - Survival 


\section{INTRODUCTION}

Meningiomas are usually benign, solid tumors with a classic appearance on CT and MRI that account for approximately 13 - $40 \%$ of the intracranial neoplasms, making it the second most common intracranial tumor in adults with an incidence of $1.5-5.5$ per $100.000[5,4,22,32,33,3,1,27,29]$. There is a female predominance [4] and most of the meningiomas are curable by surgical intervention.

Intraventricular meningiomas (IVMs) show three interesting clinopathological features that separate them from the other meningiomas. Firstly, they are extremely rare compared to other locations, accounting for only $0.5-3 \%$ of all meningiomas $[5,1,9,14]$. Secondly, they are without dural attachment. Lastly, they present a neurosurgical challenge because of their localization within the ventricular system where complete tumor resection without complications such as visual field defects may be challenging due to the proximity to the optic radiations $[29,6,8,28]$.

In this retrospective investigation, we wanted to describe our own series of 22 IVMs operated at Oslo University Hospital (OUS) between 1990 and 2010 to study the clinical features, outcome and complications related to surgical resection. 


\section{MATERIALS AND METHODS}

\section{Patients}

A total of 1469 consecutive craniotomies for intracranial meningiomas carried out at OUS in the time period 1990-2010 was investigated. From this cohort, we identified 22 patients with IVMs, 8 at Ullevål and 14 at Rikshospitalet. This accounts for $1.5 \%$ of the intracranial meningiomas resected in this period.

Clinical information was retrospectively reviewed using patients' medical and surgical records. The preoperative post-contrast imaging studies were reviewed to confirm the location, contrast enhancement, calcification and size of the tumors, as well as the presence of hydrocephalus (HC). The extent of resection was based on a subjective surgical impression of gross total (GTR) versus subtotal (STR) resections obtained from the surgeon's operative notes. Postoperative CT scans or MRIs were also reviewed to confirm complete tumor removal. Each surgical case was approached attempting total tumor removal.

Assessment of Karnofsky Performance Score (KPS) [17] was done using clinic records of preoperative visits. Neurological status preoperatively, immediately postoperatively, and at 6 months after surgery or at the time of last follow-up was also recorded. Only deficits caused by surgery were included for further analysis. Visual field defects were generally assessed ad modum Donders, unless consulted by an ophthalmologist.

The endpoint of the study was overall survival, defined as time from resection to death. Vital status (alive or dead) and time of death have been obtained from the Norwegian Population Registry (Folkeregisteret) on January 21st 2011. Surgical mortality is defined as death of any cause within 30 days after surgery.

\section{Ethics}

The study was approved by the Data Protection Official at OUS. 


\section{RESULTS}

\section{Patient characteristics}

This study included 22 patients with median age at surgery of 57 years (range 26-81, mean 52), with a male-to-female ratio of 6:16. Median observation time was 4.4 years (range $0.92-19.75$, mean 6.3 years). 20 of the patients (91\%) had a preoperative KPS $\geq 70$. The most common presenting symptoms were headache, vertigo, nausea/vomiting and mental disturbances. On neurological examination, the most common signs were impairment of balance (positive Romberg test) and pyramidal motor disturbances (Table 1).

\section{Radiology}

All of the patients underwent CT scan, MRI or both preoperatively. Radiology scans for one patient were unavailable for review, leaving 21 cases with confirmed radiology. Of these, all tumors were contrast enhanced: homogenous in 16 cases and heterogeneous in five. Four of the tumors were calcified. Maximal tumor size ranged from $1.9-7.0 \mathrm{~cm}$, with a mean size of $3.8 \mathrm{~cm} .70 \%$ of the tumors were three $\mathrm{cm}$ or more. HC was confirmed in eleven cases.

\section{Surgical treatment}

The indication for surgery was a symptomatic tumor in all but one case. One asymptomatic tumor was resected due to documented growth after careful consideration of risk versus benefit.

20 of the 22 tumors (91\%) were located in the lateral ventricles, all of them in the trigone area. One was located in the third ventricle and one in the fourth ventricle.

A parieto-occipital transcortical approach was used for all tumors located in the left and right lateral ventricle, being $8(36 \%)$ and $12(55 \%)$ respectively. An anterior transcortical route was carried out for the third ventricle tumor, whereas a posterior fossa approach through foramen Magendie was employed for the fourth ventricle tumor. 
Complete tumor removal was achieved in 21 of 22 cases $(95 \%)$. Resection of the third ventricular meningioma was subtotal due to adhesion to a central vein near the foramen of Monro.

Histology of the tumors demonstrated WHO grade I in 20 cases (90\%) and WHO grade II (atypical) in two cases (10\%). None of the primary tumors was WHO grade III (anaplastic); however, one of the resected WHO grade II meningiomas recurred six months after primary surgery as a WHO grade III tumor.

\section{Surgical mortality and morbidity}

The surgical mortality was $0 \%$. None of the patients required surgical evacuation of postoperative hematomas or were reoperated on due to osteomyelitis in the bone flap. Postoperative cerebrospinal fluid (CSF) leak was not recorded in any patient and none of the patients developed postoperative $\mathrm{HC}$ requiring surgical intervention. One patient developed deep vein thrombosis after surgery, which was treated without sequelae.

\section{Neurological outcome}

Most symptoms and signs resolved immediately after surgery: headache resolved in 13 of 16 patients; nausea and vomiting resolved in all but one patient; vertigo and mental disturbances improved in 8 of 10 and 7 of 8 patients, respectively. Three patients had epileptic seizures after craniotomy, although one of these patients had also experienced seizures prior to surgery. Patients with symptoms of sensory, motor and gait disturbances all improved after surgery.

The most common neurological deficit on follow-up after surgery was visual field defects. Four patients had a new onset of contralateral quadrant anopia and one developed contralateral homonymous hemianopia. All of these patients had tumor removal via the transcortical parieto-occipital approach. One patient with postoperative quadrant anopia had visual field defect also prior to surgery.

Of the seven patients with preoperative balance impairment, four experienced improvement on follow-up, while three remained unchanged. One patient developed 
new-onset of moderate balance impairment postoperatively. Three patients with preoperative pyramidal signs resolved, while the last patient with left sided hyperreflexia was not tested regarding reflexes on follow-up. Other signs such as ataxia and sensory and trigeminal deficits all resolved. Signs and symptoms on follow-up are summarized in Table 1.

\section{Overall and retreatment-free survival}

The overall survival rates at 1-, 5- and 10-year were $96 \%, 90 \%$ and $75 \%$, respectively (Figure 1). None of the deaths during the follow-up were tumor-related.

Of the 20 patients with WHO grade I IVMs, none received retreatments during the follow-up period. However, one patient with a WHO grade II trigonal meningioma had surgery for recurrence 6 months after primary surgery. This patient presented with preoperative vertigo (the main symptom), as well as headache, nausea, motor disturbance and mental disturbance. Neurologic examination on this patient revealed a mild fine motor deficit of the right hand and inverted plantar reflexes. Immediately postoperatively, the vertigo resolved, however, the patient developed contralateral homonymous hemianopia. Six months after primary surgery, she was reoperated on due to tumor recurrence and tumor histology had become WHO grade III. 


\section{DISCUSSION}

As intraventricular meningiomas (IVMs) are infrequent, the number of published series on the subject remains low and most series refer only to a few patients. Even in Harvey Cushing's personal series of 313 intracranial meningiomas, only $1 \%$ was intraventricular [5]. In the decades following Cushing's first IVM surgery in 1916, several case series of varying, but small sizes, were published. These were thoroughly reviewed in 1965 by Delandsheer [6], who identified 175 meningiomas of the lateral ventricles in the published literature. By 1986, only 400 IVMs had been described in the literature according to Criscuolo and Symon [4]. More recently, several series have been published and in 2003 Nakamura et al. [29] identified 132 new published cases of IVMs since 1986, leaving a total of 532 cases described in the world literature. Tables 2 and 3 summarize the key findings of published surgical series involving nine or more patients with IVMs since 2003 [1,29,28,2,24,25,11,20,30,34].

\section{Incidence}

Although meningiomas account for approximately $13 \%$ - $40 \%$ of all intracranial tumors in adults and are the second most common brain tumor, only $0.5-3 \%$ of the meningiomas are intraventricular. In our study, 22 of 1471 meningiomas were intraventricular, accounting for $1.5 \%$.

Female predominance is reported in the literature, ranging from $41 \%$ to as much as 82 $\%$ [4], with an average male-to-female ratio of 1:2 [24] although some have found a male predominance [2]. We observed a significant female predominance of $73 \%$ in our series. In general, the risk of developing meningioma increases with age [3]. During the past decade, the reported mean age of resected IVMs has varied from 35 to 47 years (Table 2). In our series, the mean age was 52 years (median 57), with a wide range from 26 to 81 years, compared to mean age of 58 years (median 58) in our total meningioma cohort of 1469 patients (unpublished results).

As summarized by Nakamura in 2003: 78\% of the IVMs are located in the lateral ventricles, $16 \%$ in the third ventricle and $7 \%$ in the fourth ventricle [29]. In our series 
of 22 IVMs, 20 tumors (91\%) were located in the lateral ventricles, one in the third ventricle (5\%) and one in the fourth ventricle (5\%). The lateral ventricular meningiomas most commonly arise in the trigone area [27,24,12,7]. Although current literature appears to show a left-sided predominance $[9,24,12]$, we observed a rightsided predominance $(60 \%)$ in our series (Table 3$)$.

\section{Clinical presentations}

IVMs do not present with a specific clinical syndrome, although Cushing and Eisenhardt defined five clinical features of trigonal IVMs in 1938: 1) pressure symptoms (often unilateral headache); 2) contralateral homonymous hemianopia (frequently macula splitting); 3) contralateral sensorimotor deficit (sensory involvement greater than motor involvement and sometimes trigeminal involvement); 4) cerebellar affection ( $>50 \%$ ); and 5) dysphasic and paralexic disturbance in leftsided tumors [5]. In contrast, Gassel and Davis stated in 1961 that the lateral ventricles are the most silent sites of the meningiomas and that IVMs often are among the largest intracranial tumors [10]. It is suggested by Winkler et al. [35] that symptoms and signs of lateral ventricle IVMs may be caused both by raised intracranial pressure and direct pressure on the adjacent cerebral parenchyma. Thus, the clinical presentation correlates with localization of the tumor within the ventricular system, the size of the tumor and its directional growth [35].

IVMs generally grow slowly and often reach an extensive size before becoming symptomatic, unless located such that CSF circulation is compromised at an early stage. The most frequently reported symptoms and signs described in literature are consequences of increased intracranial pressure. Headache, nausea, vomiting and visual disturbances are seen in $40-80 \%$ of the patients $[1,27,12]$. Other frequently reported clinical features include mental disturbances, gait disturbances, epileptic attacks and sensorimotor deficits [35]. Headache was the most common presenting symptom in our series, followed by vertigo, mental disturbance and nausea/vomiting. Impairment of balance was the most common sign on neurological examination, followed by signs of pyramidal motor disturbances. Of the five clinical features described by Cushing and Eisenhardt, in our study, only two patients presented with 
contralateral homonymous hemianopia, one had arm dysesthesia in addition to decreased sensitivity in the upper trigeminal area, two patients presented with cerebellar affection and none were dysphasic or paralexic (Table 1).

Tumors of the third and fourth ventricle usually present with symptoms and signs of HC because of obstruction of the CSF flow [27]. This was observed in our study, with $\mathrm{HC}$ confirmed by radiology in both relevant patients. The patient with a fourth ventricle meningioma experienced headache and nausea/vomiting and a positive Romberg test, whereas the patient with a third ventricular meningioma presented with headache and impaired memory and no neurological deficit.

\section{Surgical treatment}

IVMs have a classic radiologic appearance like other meningiomas, appearing globular and sharply defined but without the typical dural attachment $[9,19,26]$. They are normally hyperdense with homogenous contrast enhancement and may have calcified areas on CT scans [19,21,23]. Calcification was seen in $19 \%$ of our IVMs. IVMs are often large and can sometimes reach $\geq 6 \mathrm{~cm}$ in diameter $[1,9,14,15]$. In our series, $70 \%$ of the tumors were $\geq 3 \mathrm{~cm}$ and $14 \%$ were $\geq 6 \mathrm{~cm}$.

\section{Surgical outcome}

Mortality rates in previous series varied around $25 \%$, as presented by Fornari et al. in 1981 [9]. However, over the last 25 years, most published series report very low surgical mortality and morbidity rates as most of the patients improve during the follow-up periods. During the past decade, the mortality rate has been very low (Table 3). None of our patients died as a complication of surgery.

In our series, the overall survival rates at 1,5 and 10 years were $96 \%, 90 \%$ and $75 \%$, respectively (Figure 1) and none of the deaths during the follow-up were tumorrelated. These overall survival rates are equivalent to our results for convexity meningiomas [13]. 


\section{Surgical approach}

Surgical approaches to the atrium of the lateral ventricle can be divided into three routes; 1) an anterior approach (transsylvian), 2) posterior approaches (posterior transcortical, posterior transcallosal, occipital transcortical, and supracerebellar transtentorial) and 3) lateral approaches (transtemporal and subtemporal) [18]. In our series of 22 IVMs, all 20 tumors located in the lateral ventricles were resected using a superior parieto-occipital transcortical route, the most common approach used for meningiomas located in the lateral ventricles, as well as the most suitable route for larger tumors $[34,35]$. However, as fibres of the geniculocalcarine tract run inferolaterally to the atria [31], they are vulnerable to damage by surgery [6]. We registered new-onset visual field defects in 5 out of 22 patients six months after surgery (Table 1). According to Winkler et al. [35] IVMs are often of great size when diagnosed and damage of the optic radiation occurs during dissection of the adhesion between the tumor and white matter, implying that visual damage is not a direct consequence of the parieto-occipital approach itself. Our experience is that the standard lateral parieto-occipital route is potentially harmful regarding the optic radiation, but we can not rule out that the optic radiation is damaged because of tumor resection per se and not by the approach itself. Fornari et al. [9] have suggested a sagittal paramedian incision of the parietal cortex at a distance of $4 \mathrm{~cm}$ from the midline that starts $1 \mathrm{~cm}$ behind the postcentral fissure and is continued for $4-5 \mathrm{~cm}$ as far as the parieto-occipital fissure. This more superiorly located corticotomy point may be a less harmful approach, at least with respect to visual function. However, meticulous surgical planning based on diffusion tensor imaging (DTI) tractography of the optic radiation and the use of intraoperative neuronavigation in combination with continuous visual evoked potential (VEP) monitoring as suggested by Kamada et al. [16] may help improve the outcome of visual function after surgery for IVMs. 


\section{Conclusions}

Symptomatic IVMs should be resected, and most symptoms and signs resolve immediately after surgery. The main surgical challenge is to avoid damaging the geniculucalcarine tract when approaching and resecting IVMs located in the trigone of the lateral ventricles. Preoperative DTI to map the geniculocalcarine tract should therefore be mandatory before selecting approach for tumor resection.

\section{ACKNOWLEDGMENTS}

We thank Elisabeth Elgesem and Hanne Vebenstad for excellent secretarial assistance. We thank Dr. Ane Konglund, stud. med. Filip Hasseleid, stud. med. Andreas Mathiesen and stud. med. Andreas Schei Hessen for help with data collection.

\section{CONFLICT OF INTEREST AND SOURCES OF FUNDING STATEMENT}

The authors have no conflict of interest.

\section{List of legends}

Figure 1. Kaplan-Meier Curve

Table 1. Clinical features of 22 intraventricular meningiomas

Table 2. Clinical features of 201 cases of intraventricular meningiomas

Table 3. Location, size, hydrocephalus, surgical approach, resection and mortality in 201 cases of intraventricular meningiomas 


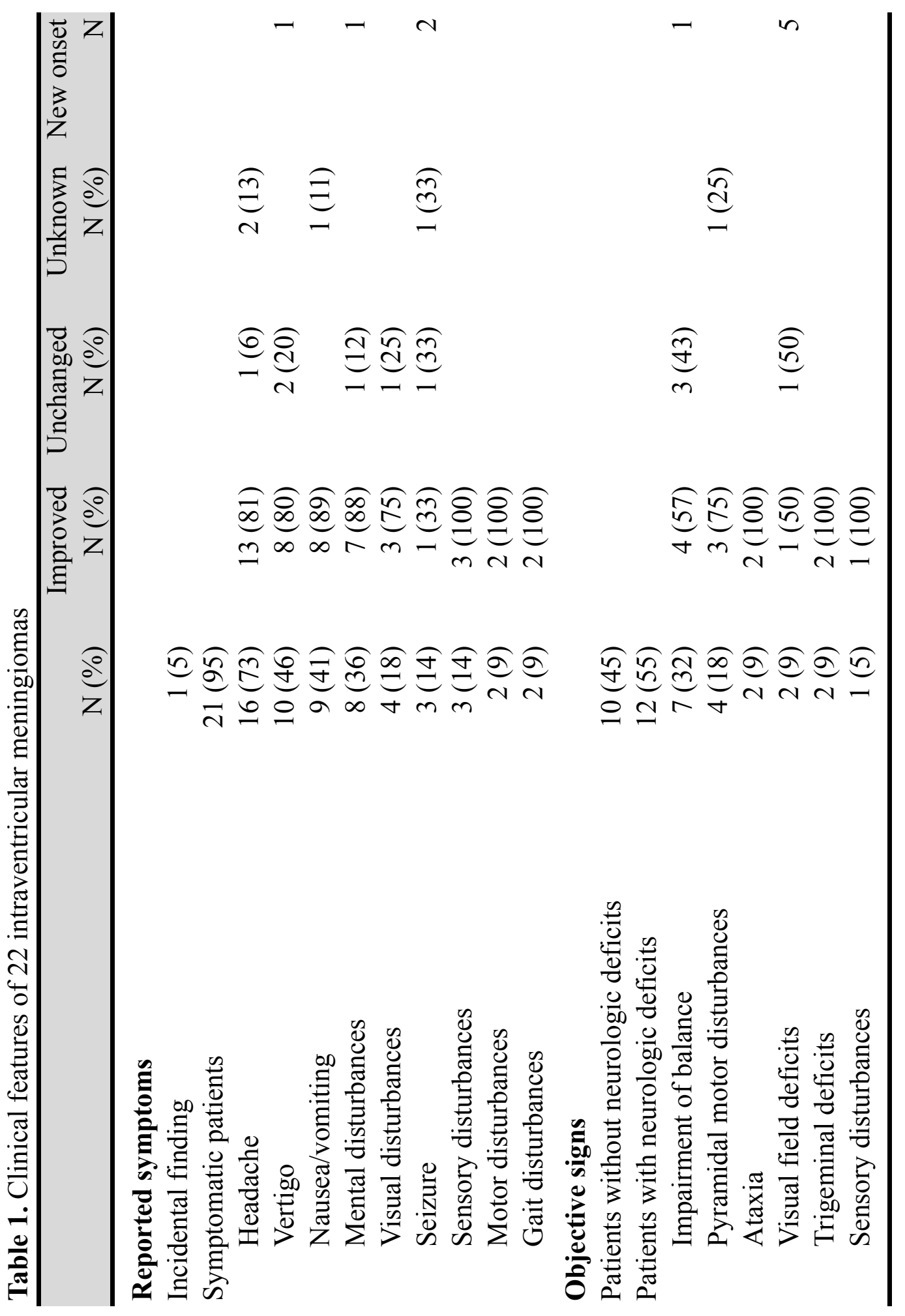




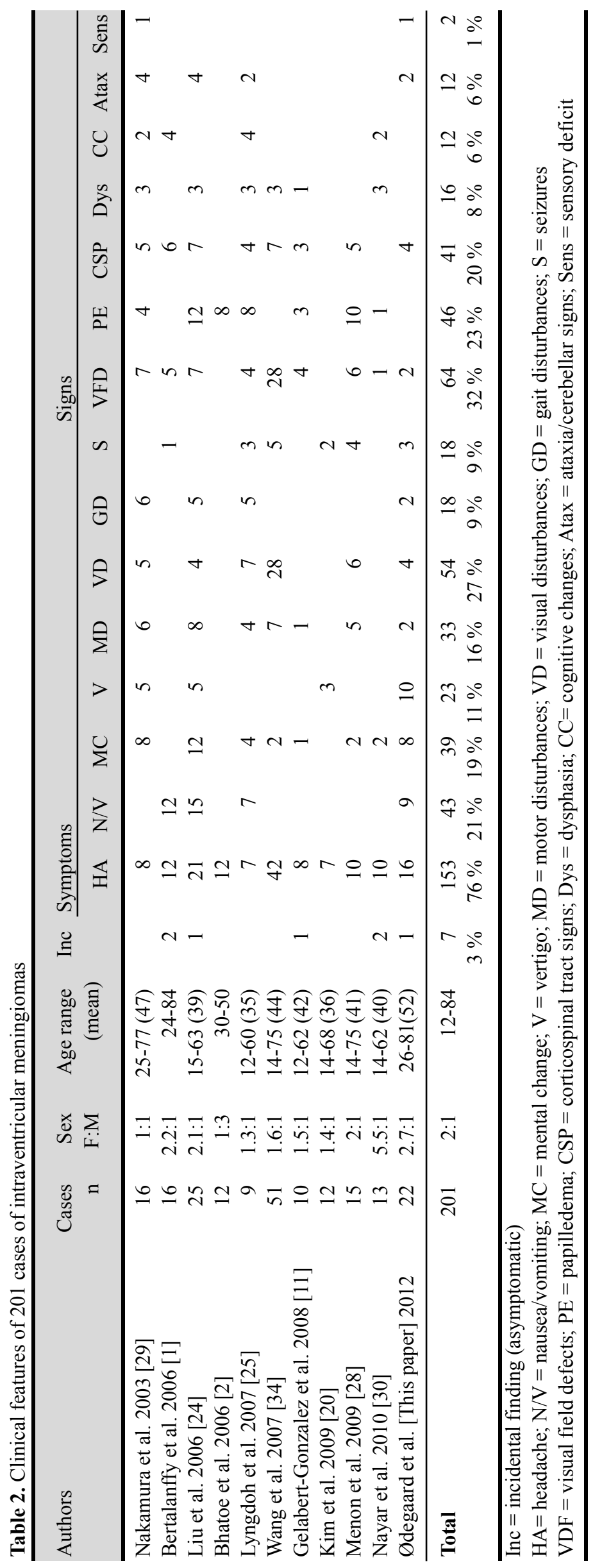




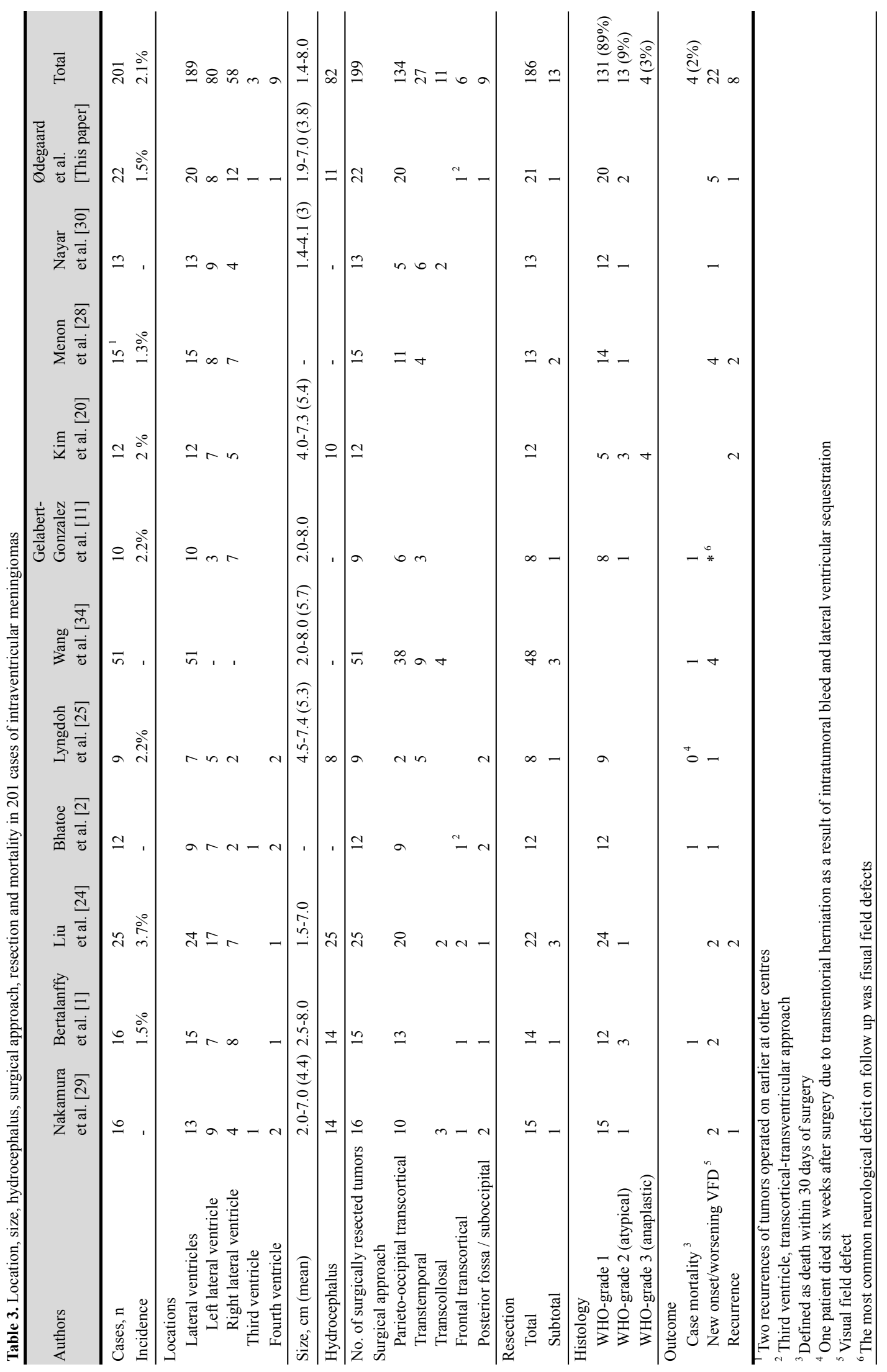


Figure 1. Kaplan-Meier Curve

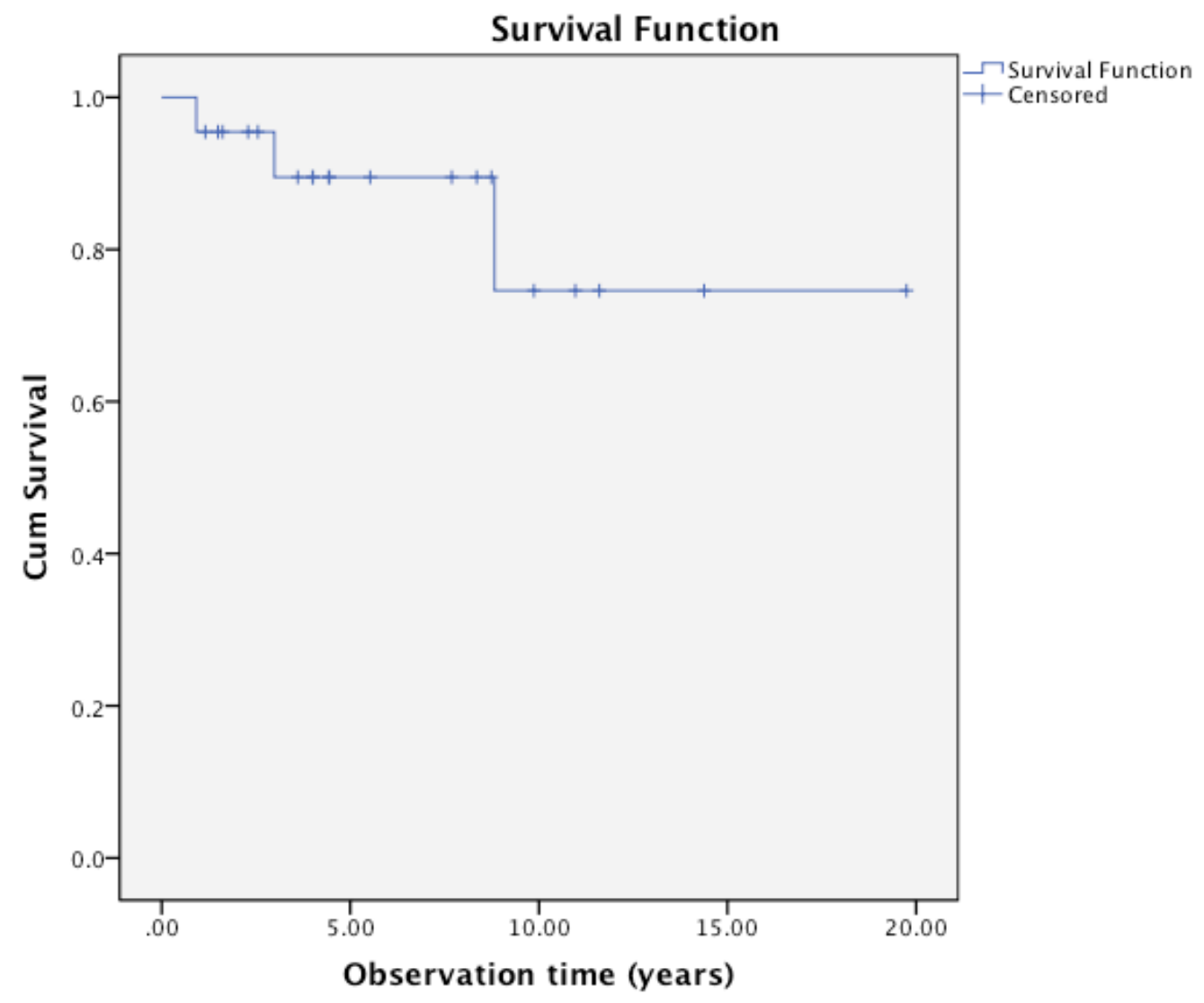




\section{REFERENCES}

1. Bertalanffy A, Roessler K, Koperek O, Gelpi E, Prayer D, Neuner M, Knosp E (2006) Intraventricular meningiomas: a report of 16 cases. Neurosurg Rev 29 (1):30-35. doi:10.1007/s10143-005-0414-5

2. Bhatoe HS, Singh P, Dutta V (2006) Intraventricular meningiomas: a clinicopathological study and review. Neurosurg Focus 20 (3):E9

3. Claus EB, Bondy ML, Schildkraut JM, Wiemels JL, Wrensch M, Black PM (2005) Epidemiology of intracranial meningioma. Neurosurgery 57 (6):1088-1095; discussion 1088-1095

4. Criscuolo GR, Symon L (1986) Intraventricular meningioma. A review of 10 cases of the National Hospital, Queen Square (1974-1985) with reference to the literature. Acta Neurochirurgica 83 (3-4):83-91

5. Cushing HL, Eisenhardt L (1938) Meningiomas: Their Classification, Regional Behavior, Life History and Surgical End Results. Charles C. Thomas, Springfield IL

6. Delandsheer JM (1965) [Meningiomas of the Lateral Ventricle]. Neurochirurgie 11:3-83

7. Delfini R, Acqui M, Oppido PA, Capone R, Santoro A, Ferrante L (1991) Tumors of the lateral ventricles. Neurosurg Rev 14 (2):127-133

8. Ellenbogen RG (2001) Transcortical surgery for lateral ventricular tumors. Neurosurg Focus 10 (6):E2

9. Fornari M, Savoiardo M, Morello G, Solero CL (1981) Meningiomas of the lateral ventricles. Neuroradiological and surgical considerations in 18 cases. J Neurosurg 54 (1):64-74. doi:10.3171/jns.1981.54.1.0064

10. Gassel MM, Davies H (1961) Meningiomas in the lateral ventricles. Brain 84:605627

11. Gelabert-Gonzalez M, Garcia-Allut A, Bandin-Dieguez J, Serramito-Garcia R, Martinez-Rumbo R (2008) Meningiomas of the lateral ventricles. A review of 10 cases. Neurocirugia (Astur) 19 (5):427-433

12. Guidetti B, Delfini R, Gagliardi FM, Vagnozzi R (1985) Meningiomas of the lateral ventricles. Clinical, neuroradiologic, and surgical considerations in 19 cases. Surg Neurol 24 (4):364-370

13. Hasseleid F, Meling TR, Rønning P, Scheie D, Helseth E Convexity meningiomas: Simpson grade I resection should still be the goal. J Neurosurg (in press)

14. Imielinski BL, Kloc W (1997) Meningiomas of the lateral ventricles of the brain. Zentralbl Neurochir 58 (4):177-182

15. Jun CL, Nutik SL (1985) Surgical approaches to intraventricular meningiomas of the trigone. Neurosurgery 16 (3):416-420

16. Kamada K, Todo T, Morita A, Masutani Y, Aoki S, Ino K, Kawai K, Kirino T (2005) Functional monitoring for visual pathway using real-time visual evoked potentials and optic-radiation tractography. Neurosurgery 57 (1 Suppl):121-127; discussion 121-127

17. Karnofsky DA (1949) The Clinical Evaluation of Chemotherapeutic Agents in Cancer. In: MacLeod CM (ed) Evaluation of Chemotherapeutic Agents. p 196

18. Kawashima M, Li X, Rhoton AL, Jr., Ulm AJ, Oka H, Fujii K (2006) Surgical approaches to the atrium of the lateral ventricle: microsurgical anatomy. Surg Neurol 65 (5):436-445. doi:10.1016/j.surneu.2005.09.033 
19. Kendall B, Reider-Grosswasser I, Valentine A (1983) Diagnosis of masses presenting within the ventricles on computed tomography. Neuroradiology 25 (1):11-22

20. Kim EY, Kim ST, Kim HJ, Jeon P, Kim KH, Byun HS (2009) Intraventricular meningiomas: radiological findings and clinical features in 12 patients. Clin Imaging 33 (3):175-180. doi:10.1016/j.clinimag.2008.09.005

21. Kloc W, Imielinski BL, Wasilewski W, Stempniewicz M, Jende P, Karwacki Z (1998) Meningiomas of the lateral ventricles of the brain in children. Childs Nerv Syst 14 (8):350-353

22. Kurland LT, Schoenberg BS, Annegers JF, Okazaki H, Molgaard CA (1982) The incidence of primary intracranial neoplasms in Rochester, Minnesota, 19351977. Ann N Y Acad Sci 381:6-16

23. Lang I, Jackson A, Strang FA (1995) Intraventricular hemorrhage caused by intraventricular meningioma: CT appearance. AJNR Am J Neuroradiol 16 (6):1378-1381

24. Liu M, Wei Y, Liu Y, Zhu S, Li X (2006) Intraventricular meninigiomas: a report of 25 cases. Neurosurg Rev 29 (1):36-40. doi:10.1007/s10143-005-0418-1

25. Lyngdoh BT, Giri PJ, Behari S, Banerji D, Chhabra DK, Jain VK (2007) Intraventricular meningiomas: a surgical challenge. J Clin Neurosci 14 (5):442-448. doi:10.1016/j.jocn.2006.01.005

26. Mani RL, Hedgcock MW, Mass SI, Gilmor RL, Enzmann DR, Eisenberg RL (1978) Radiographic diagnosis of meningioma of the lateral ventricle. Review of 22 cases. J Neurosurg 49 (2):249-255. doi:10.3171/jns.1978.49.2.0249

27. McDermott MW (2003) Intraventricular meningiomas. Neurosurg Clin N Am 14 (4):559-569

28. Menon G, Nair S, Sudhir J, Rao R, Easwer HV, Krishnakumar K (2009) Meningiomas of the lateral ventricle - a report of 15 cases. Br J Neurosurg 23 (3):297-303. doi:10.1080/02688690902721862

29. Nakamura M, Roser F, Bundschuh O, Vorkapic P, Samii M (2003) Intraventricular meningiomas: a review of 16 cases with reference to the literature. Surg Neurol 59 (6):491-503; discussion 503-494

30. Nayar VV, DeMonte F, Yoshor D, Blacklock JB, Sawaya R (2010) Surgical approaches to meningiomas of the lateral ventricles. Clin Neurol Neurosurg 112 (5):400-405. doi:10.1016/j.clineuro.2010.02.005

31. Rubino PA, Rhoton AL, Jr., Tong X, Oliveira E (2005) Three-dimensional relationships of the optic radiation. Neurosurgery 57 (4 Suppl):219-227; discussion 219-227

32. Staneczek W, Janisch W (1992) Epidemiologic data on meningiomas in East Germany 1961-1986: incidence, localization, age and sex distribution. Clin Neuropathol 11 (3):135-141

33. Surawicz TS, McCarthy BJ, Kupelian V, Jukich PJ, Bruner JM, Davis FG (1999) Descriptive epidemiology of primary brain and CNS tumors: results from the Central Brain Tumor Registry of the United States, 1990-1994. Neuro Oncol 1 (1):14-25

34. Wang X, Cai BW, You C, He M (2007) Microsurgical management of lateral ventricular meningiomas: a report of 51 cases. Minim Invasive Neurosurg 50 (6):346-349. doi:10.1055/s-2007-993205

35. Winkler PA, Buhl R, Tonn JC (2009) Intraventricular meningiomas. In: Lee JH (ed) Meningiomas: Diagnosis, Treatment and Outcome. Springer, London, pp 491-514 